\title{
Understanding 'Don't know' answers to survey questions - an International comparative analysis using interview paradata
}

DOI:

10.1080/13511610.2020.1752631

\section{Document Version}

Accepted author manuscript

Link to publication record in Manchester Research Explorer

Citation for published version (APA):

Purdam, K., Sakshaug, J. W., Bourne, M., \& Bayliss, D. (2020). Understanding 'Don't know' answers to survey questions - an International comparative analysis using interview paradata. Innovation: The European Journal of Social Science Research. https://doi.org/10.1080/13511610.2020.1752631

Published in:

Innovation: The European Journal of Social Science Research

\section{Citing this paper}

Please note that where the full-text provided on Manchester Research Explorer is the Author Accepted Manuscript or Proof version this may differ from the final Published version. If citing, it is advised that you check and use the publisher's definitive version.

\section{General rights}

Copyright and moral rights for the publications made accessible in the Research Explorer are retained by the authors and/or other copyright owners and it is a condition of accessing publications that users recognise and abide by the legal requirements associated with these rights.

\section{Takedown policy}

If you believe that this document breaches copyright please refer to the University of Manchester's Takedown Procedures [http://man.ac.uk/04Y6Bo] or contact uml.scholarlycommunications@manchester.ac.uk providing relevant details, so we can investigate your claim.

\section{OPEN ACCESS}




\section{Understanding 'Don't Know' Answers To Survey Questions - An International Comparative Analysis Using Interview Paradata}

K. Purdam, J. Sakshaug, M. Bourne and D. Bayliss 


\title{
Understanding 'Don't Know' Answers To Survey Questions - An International Comparative Analysis Using Interview Paradata
}

\begin{abstract}
If 'Don't know' answers to survey questions are not being accurately captured, understood and analysed then the validity of the estimates of public knowledge, values and attitudes can be questioned. In this article survey answers and interviewer observation paradata about how respondents answer factual, value and attitude-based survey questions were analysed. Interviewer characteristics were also taken into account. There was considerable variation in the likelihood of a 'Don't know' response at both the interviewer and country levels. Moreover, whilst most respondents were perceived by the interviewers to understand the questions, many asked for clarification. The presence of another person during the interview was also an important factor. Analysts of public attitudes need to know more about 'Don't know' answers to questions. Simply discouraging 'Don't know' answers or coding them all as non-directional responses or missing data is likely to lead to measurement error. Methodological innovations should include follow up questions in surveys as well as bespoke surveys to explore the reasons for a 'Don't know' response in more depth. Additional support for those respondents who find answering certain questions a challenge could also be introduced. It is clear a more robust and in-depth understanding of 'Don't know' responses is important for the accuracy of social surveys.
\end{abstract}

Key Words: Ambivalence, Attitudes, Don't Know, Measurement Error, Paradata

\section{Introduction}

If 'Don't know' answers to survey questions are not being accurately captured, understood and analysed, then the validity of the estimates of public knowledge, values and attitudes can be questioned. This is a particularly important issue in the context of concerns about the accuracy of opinion polling and the often substantial levels of 'Don't know' responses. It is notable that in a number of countries opinion polls have failed to predict election results. The enquiries in the UK and the USA into polling accuracy have recommended, alongside issues relating to the sampling, a more detailed exploration of the nature of 'Don't know' responses (AAPOR, 2017; Silver, 2016; Sturgis et al., 2016).

A 'Don't know' answer can be the result of different factors including: (i) the respondent being uncertain due to not having enough knowledge (or up-todate knowledge); (ii) a lack of understanding including in relation to the format and wording of the questions; (iii) ambivalence in terms of being indifferent, having mixed feelings or a conflicted attitude on a particular issue and; (iv) having a directional view but not wanting to express it due to social desirability, which can be linked to issues of confidentiality, and/or a desire to remain silent due to a fear of the consequences of expressing a directional view (Noelle- 
Neumann, 1984).

Research by Krosnick (1991) outlined the theory of satisficing where respondents take cognitive short cuts when answering survey questions and so do not provide complete or accurate information. Survey respondents often answer questions very quickly (Bassili and Fletcher, 1991) and responding 'Don't know' can be a cost-saving heuristic, including in relation to the respondent not having had a chance to think about the issues the question has raised and also being skeptical of the survey process itself. It can also be a form of refusal, driven by a respondent's discontent with the response options available. Research using experimental designs and follow-up questions has also examined the nature of 'Don't know' responses in surveys (Alwin, 2007; Malhotra et al., 2009; Schuman and Presser, 1981; Shoemaker et al., 2002; Tourangeau et al., 2000). Contingent valuation based methods, where respondents are given background information, have identified how the selection of what have been termed 'non-opinion' options is highest amongst respondents with lower education qualifications (Converse and Presser, 1986; Krosnick et al., 2002).

Research has identified different types of ambivalence, including distinguishing between what has been described as objective ambivalence (measured by comparing people's answers to questions) and subjective or metapsychological ambivalence (explicitly asking people to state how ambivalent they are) (Craig et al., 2002; Holbrook and Krosnick, 2005; Lavine, 2001; Martinez et al., 2012). Ambivalence has been shown to be associated with more unstable attitudes and lower levels of political engagement (Alvarez and Brehm, 2002; Johnson, 2014). Rudolph and Popp (2007) argue that ambivalence is a function of the cognitive effort involved in forming political judgments. They found that ambivalence varies in relation to the information an individual has available, their motivation and their cognitive style. Exposure to heterogeneous information was shown to be associated with increased ambivalence. However research in psychology has also identified how some people prefer to avoid uncertainty and dissonance (Festinger, 1957). The removal of 'Don't know' options from attitudinal scales has been shown to encourage some respondents to provide directional responses that they would have otherwise withheld, but which were consistent with answers given to questions about similar issues when a 'Don't know' option was included (Bradburn and Sudman, 1988; Gilljam and Granberg, 1993). Research by Kuha et al., (2018) has revealed how follow up probes can help respondents give a directional response. However there is a time cost to this and there can be a measurement effect as the probe can affect the response given.

The mode of the survey and the identity of the interviewer and how they behave have also been shown to affect the responses given (O'Muircheartaigh and Campanelli, 1998; Tourangeau et al., 2000). Moreover, question format and the layout of on-line and video surveys have also been found to impact on responses, including affecting the frequency of 'Don't know' answers (Couper, 2008; Haan et al., 2017; Heerwegh, 2005; Miller and Orr, 2008; Robison, 2015; Robmann et al., 2017; Zeglovits and Schwarzer, 2016).

It is notable that respondents who answer 'Don't know' can take longer to answer and so such answers are thought to be a combination of genuine 
uncertainty and satisficing responses (Turner et al., 2015). Research has also shown how older respondents and those with lower levels of education qualifications have been found to take longer to answer questions (Knowles and Condon, 1999). Research has also suggested that a respondent might select an answer without thinking to give the impression of having a directional view on an issue (Arcuri et al., 2008; Converse, 1970; Luskin and Bullock, 2011). Research by Sturgis et al., (2014) has identified latent attitudes, or what the authors term 'hidden don't knows', where respondents give a mid-point response rather than a 'Don't know' response, even though they were critically engaged with the issues the questions were addressing and were actually undecided. Research has identified how substantial numbers of people provide responses to questions about their attitudes towards organisations and policies that do not actually exist (Bishop, 2004; Sturgis and Smith, 2010).

However, despite the prevalence and importance of 'Don't know' responses there has only been limited cross-national research on how they can vary at the country and the interviewer level and in relation to factual, value and attitude-based questions. Cross-national comparative research has identified the variations in response rates to surveys at the country and local levels including in relation to survey mode, fieldwork resources, contact data quality, fieldworker experience, household type, privacy concerns and declining levels of trust (Beullens et al., 2018; Couper and De Leeuw, 2003; Lyness and Brumit Kropf, 2007). Research has also shown country variations in socially desirable responses to survey questions (Johnson and van de Vijver, 2003; He et al., 2015). Moreover, evidence suggests variations in values, attitudes and voting behaviour at the country and local levels including in relation to the social and political context, political freedom, equality, religious belief and electoral system (Cancela and Geys, 2016; Franklin, 2004; Inglehart, 2010; International IDEA, 2017; Luijkx et al., 2019).

In this article 'Don't know' responses in relation to factual, value and attitudebased survey questions are examined by analysing interviewer observation paradata from the European Social Survey (ESS). Paradata describes a wide range of data generated from conducting a survey including: call records, interviewer characteristics, interview length and keystroke data (Kreuter, 2018a; 2018b). Paradata has been used to examine and help explain nonresponse error and interviewer effects and to improve survey design (Couper, 1998; Couper and Kreuter, 2013; Groves and Heeringa, 2006; Nicolaas, 2011). In the ESS paradata describes the questions completed by the interviewer about their observations of the respondents during the interview. Using interviewer observation paradata to explore 'Don't know' answers to survey questions could add considerably to the existing evidence base and understanding in this area.

Key Research Questions: (i) What types of survey questions do people give a 'Don't know' response to? (ii) How does the likelihood of a 'Don't know' response vary in terms of key demographics, across countries and between survey interviewers? (iii) To what extent can interviewer observation paradata about how people answer questions inform the understanding of 'Don't know' responses and contribute to more accurate measurement of public values, attitudes and knowledge? 


\section{Method and Data}

'Don't know' answers and respondent understanding of questions were examined by analysing respondents' answers alongside observation paradata from interviewers about how respondents engaged with questions from the 2014 European Social Survey (ESS).

The ESS is a high quality cross-sectional face-to-face survey, which has been conducted biennially since $2001 .{ }^{1}$ During its existence, the ESS has covered more than 30 countries. Random probability methods are used to derive representative samples of the population aged 15 and over. $^{2}$ The average sample size for each country was around 1,900 in 2014. The questionnaires were designed in English and then translated and tested by national teams into the first language of each country. The ESS covers a wide range of social and political issues. The paradata about how the respondent answered and engaged with questions is produced by the interviewer once the interview has been completed.

\section{Analysis and Question Types - Factual, Value and Attitude-Based}

Firstly, all the survey questions in terms of the level of 'Don't know' responses were ranked and the differences across factual, value and attitude-based questions were examined. A factual-based question is one where the answer is reliant on the respondent's knowledge of facts; for example, how old they are. A value question attempts to capture an individual's underlying belief about an issue and an attitudinal question is designed to capture a respondent's views on a specific issue (Inglehart, 2003).

Secondly, interviewers' observations were analysed in terms of respondents' engagement with the questions including: (i) whether they tried to answer the questions to the best of their ability; (ii) whether they understood the questions; (iii) whether they asked for clarification; (iv) whether they were reluctant to answer; and (v) whether there was anyone else present who 'interfered' with the interview. ${ }^{3}$ All the interviewer observation questions had completion rates of at least 99 per cent.

Finally, multilevel logistic regression modeling was used to examine respondents' likelihood of answering 'Don't know'. The use of multilevel modelling allows us to explore the variation in the outcome of interest, both between countries and between interviewers. The modelling details are given in the findings section below (and in the Appendix). The limitations are considered in the discussion section including in relation to the use of multilevel modelling approaches given the limited number of countries in the ESS (Bryan and Jenkins, 2016). 


\section{Results}

\section{Question Types (Factual, Value and Attitude) and 'Don't Know' Responses}

All the questions across the ESS that had a 'Don't know' option were ranked in terms of the level of 'Don't know' responses. The table below lists the ten questions which had the highest levels of 'Don't know' responses. Drawing on the discussion above, the types of questions were coded in terms of whether it is asking for a factual, value or attitude-based response.

Table 1. The questions with the highest levels of 'Don't know' response

\begin{tabular}{|c|c|c|c|c|}
\hline Rank & Question wording & $\begin{array}{l}\text { Type of } \\
\text { question } \\
\text { (Factual, } \\
\text { Value, } \\
\text { Attitude) }\end{array}$ & $\begin{array}{l}\text { Total } \\
\text { number of } \\
\text { responses }\end{array}$ & $\begin{array}{l}\text { \% of } \\
\text { responses } \\
\text { which were } \\
\text { 'Don't } \\
\text { know' }\end{array}$ \\
\hline 1 & $\begin{array}{l}\text { What is the highest level of education of } \\
\text { your father? }\end{array}$ & $\mathrm{F}$ & 38,487 & 10.2 \\
\hline 2 & $\begin{array}{l}\text { In politics people sometimes talk of "left" } \\
\text { and "right". Using this card, where would } \\
\text { you place yourself on this scale, where } 0 \\
\text { means the left and } 10 \text { means the right? }\end{array}$ & $\mathrm{V}$ & 40,185 & 9.6 \\
\hline 3 & $\begin{array}{l}\text { Out of every } 100 \text { people living in your } \\
\text { country, how many do you think were } \\
\text { born outside your country? }\end{array}$ & F/A & 40,185 & 8.7 \\
\hline 4 & $\begin{array}{l}\text { On a scale of } 0-10 \text { how much do you } \\
\text { personally trust the European Parliament? }\end{array}$ & $A$ & 40,185 & 8.1 \\
\hline 5 & $\begin{array}{l}\text { On a scale of } 0-10 \text { how much do you } \\
\text { personally trust the United Nations? }\end{array}$ & $A$ & 40,185 & 7.9 \\
\hline 6 & $\begin{array}{l}\text { Which category describes your household } \\
\text { income? }\end{array}$ & $\mathrm{F}$ & 38,134 & 6.5 \\
\hline 7 & $\begin{array}{l}\text { What is the highest level of education of } \\
\text { your mother? }\end{array}$ & $\mathrm{F}$ & 38,487 & 6.4 \\
\hline 8 & $\begin{array}{l}\text { Thinking about the world today, would you } \\
\text { say that some cultures are much better } \\
\text { than others or that all cultures are equal? }\end{array}$ & $A$ & 40,185 & 6.4 \\
\hline 9 & $\begin{array}{l}\text { Compared to people like yourself who } \\
\text { were born here, how do you think the } \\
\text { government treats those who have } \\
\text { recently come to live here from other } \\
\text { countries? }\end{array}$ & $A$ & 40,185 & 5.4 \\
\hline 10 & $\begin{array}{l}\text { Which party did you vote for at the last } \\
\text { election? }\end{array}$ & $\mathrm{F}$ & $27,869^{*}$ & 4.7 \\
\hline
\end{tabular}

Note: *This is based on the subpopulation of those who said they voted.

The highest levels of 'Don't know' responses occur across factual, value and attitude-based questions and in relation to very different types of issues in the survey. Whilst the scope of the issues covered in the survey is limited, this still provides some new insights into the range and type of questions to which respondents provide 'Don't know' answers. 
In order to examine these issues in detail a selection of six of the ten questions are considered in more depth. The levels of 'Don't know' responses to four of these selected questions are also shown in Figure 1. It is not possible in an article of this length to examine all the questions in such detail but the analysis below provides insights across the three question types - factual, value and attitude-based. Results for the other questions are available from the authors on request.

\section{Factual-Based Questions and ‘Don’t Know’ Responses}

Firstly, the question: 'What is the highest level of education of your father?' was examined. This question provides a list of qualification options, an 'Other' and a 'Don't know' response option. It is a factual-based question, but a person's response is likely to be influenced by their age and recall. It may also be influenced by their experiences and by social desirability bias.

Overall 10 per cent of respondents stated that they 'Don't know' the highest education level of their father. There was no difference in terms of the gender of the respondents. Younger people aged 20 to 29 years old were less likely to state that they 'Don't know' (10 per cent) compared to those aged 70 to 79 years old (16 per cent). Those respondents with no or low-level education qualifications were more likely to state they 'Don't know' (18 per cent) compared to those with the highest level of qualifications (6 per cent). There were also striking differences between countries. For example, in Denmark only 3 per cent of respondents stated that they 'Don't know' compared to 17 per cent of respondents in Estonia, 18 per cent of respondents in Lithuania, 19 per cent of respondents in France and 21 per cent of respondents in Great Britain.

The political party the respondent voted for at the last election was then examined: 'Which party did you vote for at the last election?' The question lists the different political parties in each country and provides write-in options for: 'Other party', 'Refuse to answer' and 'Don't know'.

Overall 5 per cent of respondents stated that they 'Don't know' which party they voted for at the last election. There was little difference in terms of the gender of the respondents. Young people aged under 20 years old were more likely to state that they 'Don't know' (12 per cent) compared to 4 per cent of those aged 60 years and older. There was very little difference in terms of education qualifications. There were again considerable differences across countries, as shown in Figure 1(a). For example, in Israel no respondents stated that they 'Don't know' compared to 15 per cent of respondents in Lithuania and Slovenia, and 18 per cent of respondents in Poland. Of course, recalling who you voted for is likely to be affected by how recent the election was and, in general, more people tend to recall voting than actually did (Curtice and Sparrow, 2010; Holbrook and Krosnick, 2010).

A factual-based question, to which the answer depends on a person's knowledge and also their attitudes and experiences was also examined: 'Out of every 100 people living in your country how many do you think were born outside the country?' Respondents were asked to give a numerical figure. If they gave a 'Don't know' response they were prompted to give a 'best 
estimate' but could also still give a 'Don't know' response.

In total out of all of the respondents 9 per cent stated that they 'Don't know' how many people were born outside the country. There was little difference in terms of the gender of the respondents. Young people aged under 20 years old were less likely to state that they 'Don't know' (6 per cent) compared to 16 per cent of those aged between 70 and 79 years old and 22 per cent of those aged 80 years and older. Those respondents with no or low-level education qualifications were more likely to state they 'Don't know' (15 per cent) compared to those with the highest level of qualifications (5 per cent). As shown in Figure 1(b), there were also considerable differences between countries. For example, no respondents in Belgium or Portugal stated that they 'Don't know' compared to 18 per cent of respondents in Hungary and Lithuania, and 29 per cent of respondents in Poland. ${ }^{4}$

\section{Value-Based Questions and ‘Don’t Know’ Responses}

Value-based questions and, in particular, political orientation were also examined: "In politics people sometimes talk of "left" and "right". Using this card, where would you place yourself on this scale, where 0 means the left and 10 means the right?' The question includes a numerical midpoint (but it is not labeled) and an option to give a 'Don't know' response.

Overall 10 per cent of respondents stated that they 'Don't know' where they would place themselves on a left-right scale. There was little difference in terms of the gender of the respondents. Young people aged under 20 years old were more likely to state that they 'Don't know' (18 per cent) compared to those aged between 70 and 79 years old ( 6 per cent). Respondents with no or low-level education qualifications were more likely to state they 'Don't know' (13 per cent) compared to those with the highest level of qualifications (4 per cent).

Again there were considerable differences between countries. For example, as shown in Figure 1(c), 3 per cent of respondents in Norway stated that they 'Don't know' compared to 27 per cent of respondents in Slovenia and 33 per cent of respondents in Lithuania.

\section{Attitude-Based Questions and ‘Don’t Know’ Responses}

Trust is an attitude, but one that can be linked to a person's underlying values. Responses to the question: 'On a scale of 0-10 how much do you personally trust the European Parliament?' were examined. The question includes a numerical midpoint (but this is not labeled) and an option to give a 'Don't know' response.

Overall 8 per cent of respondents stated that they 'Don't know' how much they trust the European Parliament. There was little difference in terms of the gender of the respondents. Young people aged under 20 years old were more likely to state that they 'Don't know' (10 per cent) compared to 5 per cent of those aged 50-59 years old, however 20 per cent of those aged 80 years and older stated that they 'Don't Know'. Those respondents with no or low-level education qualifications were more likely to state they 'Don't know' (14 per 
cent) compared to those with the highest level of qualifications (4 per cent). There were also striking differences between countries, as shown in Figure 1(d). For example, only 1 per cent of respondents in Belgium stated that they 'Don't know' compared to 38 per cent of respondents in Israel. As discussed below, this may be explained by Israel's political and geographic distance from Europe.

Finally, an attitude-based question concerning people's views towards different cultures was examined: 'Thinking about the world today, would you say that some cultures are much better than others or that all cultures are equal?' (Some cultures are much better than others 1; All cultures are equal 2). Respondents had the option to give a 'Don't know' response.

Overall 6 per cent of respondents stated that they 'Don't know' if "some cultures are much better than others or that all cultures are equal". There was no difference in terms of the gender of the respondents. Young people aged under 20 years old were less likely to answer 'Don't know' (4 per cent) compared to 13 per cent of those aged 80 years and older. There was little difference in terms of education qualification levels. There were considerable differences across countries. For example, only 1 per cent of respondents in Belgium and 2 per cent of respondents in France, Norway and Portugal stated that they 'Don't know' compared to 11 per cent of respondents in Lithuania, 13 per cent of respondents in Poland, and 14 per cent of respondents in Austria.

Figure 1 below provides a summary of 'Don't know' responses to four of the selected questions discussed above.

Figure 1. Country-level differences in 'Don't know' responses.

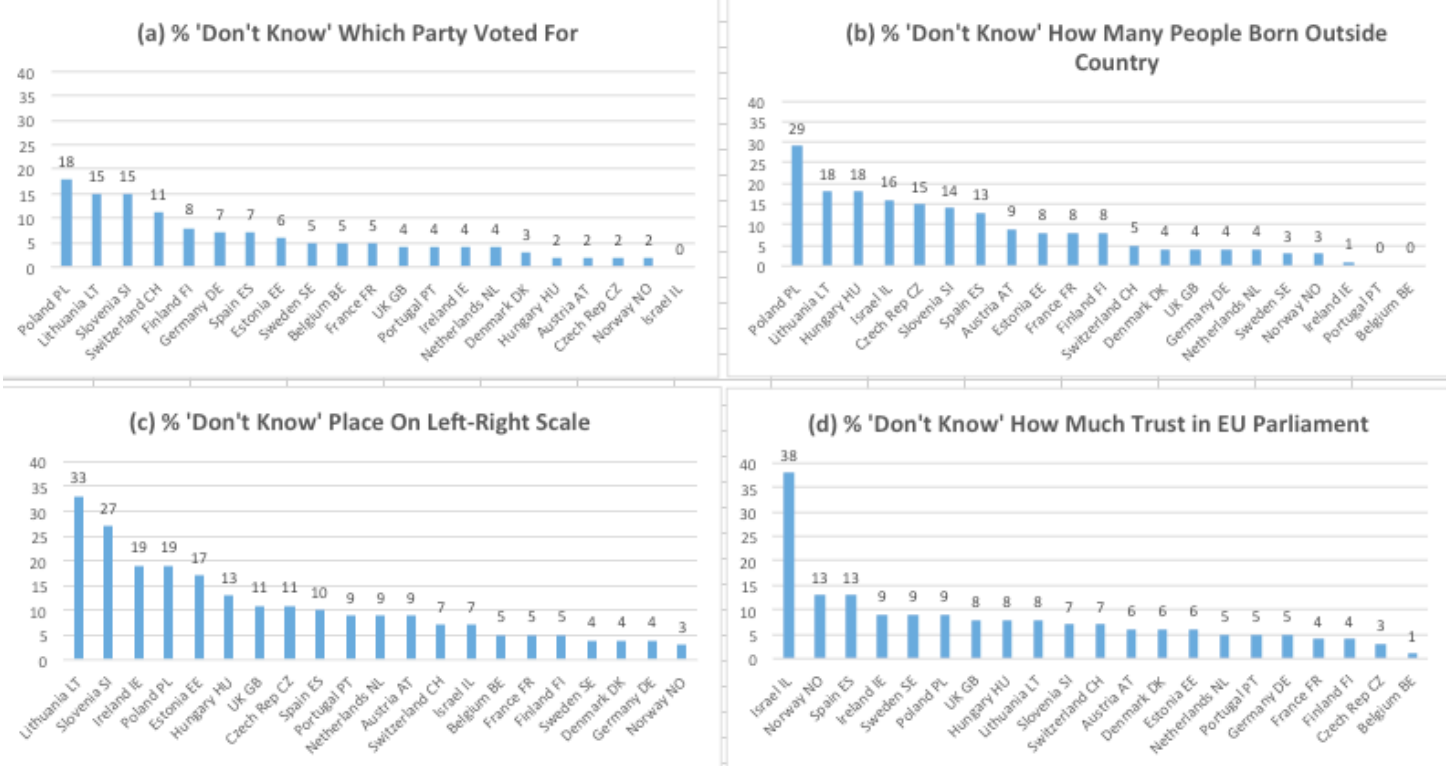

The interviewer observation paradata about how the survey respondents engaged with and answered the questions are now examined.

Interviewers' Observations of Survey Respondents 
The interviewers' perceptions of whether respondents were answering questions to the 'best of their ability' are shown in Table 2 below.

Table 2. Did you feel that the respondent tried to answer the questions to the best of his or her ability?

\begin{tabular}{|l|r|r|}
\hline $\begin{array}{l}\text { Respondent tried to answer questions to best of their } \\
\text { ability? }\end{array}$ & Freq & $\%$ \\
\hline 1. Never & 759 & 1.3 \\
\hline 2. Almost never & 572 & 0.8 \\
\hline 3. Now and then & 1,933 & 2.6 \\
\hline 4. Often & 7,214 & 16.7 \\
\hline 5. Very often & 29,422 & 78.3 \\
\hline Total & 39,900 & 100 \\
\hline
\end{tabular}

Note: Tables 2-5 show raw counts and weighted percentages.

Most respondents (95 per cent) were perceived to have tried often or very often to have answered the questions to the best of their ability. There was no difference in terms of the gender, age or qualification level of the respondents. Perhaps highlighting the challenge of conducting surveys, 5 per cent of respondents never, almost never or only now and then answered the question to the best of their ability. Moreover, as shown in Figure 2(a) there were substantial differences between countries with 1 per cent of respondents in Finland and Norway perceived as never, almost never or only now and then answering questions to the best of their ability compared to 31 per cent of respondents in Lithuania.

The interviewers' perceptions of the extent to which they felt respondents understood the questions are shown in Table 3.

Table 3. Overall, did you feel that the respondent understood the questions?

\begin{tabular}{|l|r|r|}
\hline $\begin{array}{l}\text { Overall, did you feel that the respondent understood the } \\
\text { questions? }\end{array}$ & Freq & \% \\
\hline 1. Never & 245 & 0.5 \\
\hline 2. Almost never & 367 & 0.8 \\
\hline 3. Now and then & 2,306 & 4.9 \\
\hline 4. Often & 10,112 & 25.5 \\
\hline 5. Very often & 26,964 & 68.1 \\
\hline Total & 39,994 & 100 \\
\hline
\end{tabular}

Overall the perceived level of respondent understanding of the questions was high. There was no difference in terms of the gender of the respondents. 6 per cent of those aged under 20 years old were viewed as never, almost never or only now and then having understood the questions compared to 14 per cent of those aged 80 years and older. Of those people with the highest level of qualifications, only 3 per cent were viewed as never, almost never or only now and again understanding the questions compared to 15 per cent of people with no or the lowest level of qualifications. Again there were differences between 
countries as shown in Figure 2(b). Only 2 per cent of respondents in Finland were perceived as never, almost never or only now and again understanding the questions compared to 23 per cent of respondents in Israel.

The extent to which respondents asked for clarification of any questions during the interview was also revealing as shown in Table 4.

Table 4. Did the respondent ask for clarification on any questions?

\begin{tabular}{|l|r|r|}
\hline Did the respondent ask for clarification on any questions? & Freq & $\%$ \\
\hline 1. Never & 15,555 & 39.3 \\
\hline 2. Almost never & 13,183 & 33.7 \\
\hline 3. Now and then & 8,505 & 20.4 \\
\hline 4. Often & 1,991 & 4.8 \\
\hline 5. Very often & 868 & 1.8 \\
\hline Total & 40,102 & 100 \\
\hline
\end{tabular}

Overall 27 per cent of respondents very often, often or now and then asked for clarification. There was no difference in terms of the gender of the respondents. 22 per cent of younger people aged 20-29 years old very often, often or now and then asked for clarification compared to 38 per cent of those aged 70-79 and 53 per cent of those aged 80 years and older. 48 per cent of respondents with no or the lowest level of qualifications very often, often or now and then asked for clarification compared to 17 per cent of those with the highest level of qualifications. There were also substantial differences across countries as shown in Figure 2(c). 18 per cent of respondents in Finland and the Netherlands very often, often or now and then asked for clarification compared to 46 per cent of respondents in Lithuania and Israel.

The interviewers' perceptions of respondents being reluctant to answer questions are shown in Table 5.

Table 5. Did you feel that the respondent was reluctant to answer any questions?

\begin{tabular}{|l|r|r|}
\hline $\begin{array}{l}\text { Did you feel that the respondent was reluctant to answer } \\
\text { any questions? }\end{array}$ & Freq & \% \\
\hline 1. Never & 25,282 & 70 \\
\hline 2. Almost never & 8,414 & 18.2 \\
\hline 3. Now and then & 4,575 & 8.5 \\
\hline 4. Often & 994 & 1.7 \\
\hline 5. Very often & 741 & 1.3 \\
\hline Total & 40,006 & 100 \\
\hline
\end{tabular}

Overall 12 per cent of respondents were viewed as very often, often or now and then reluctant to answer questions. There was no difference in terms of the gender of the respondents, but there was some evidence of difference by age: 9 per cent of those aged under 20 years old were viewed as very often, often or now and then reluctant to answer questions compared to 15 per cent of those aged 70 and older. 18 per cent of those respondents with no or the 
lowest level of qualifications were viewed as being very often, often or now and then reluctant to answer questions compared to 8 per cent of those with the highest level of qualifications.

As shown in Figure 2(d) there were again substantial differences between countries, with 4 per cent of respondents in Norway perceived to be reluctant to answer questions now and then, often or very often compared to 36 per cent of respondents in Hungary and 44 per cent of respondents in Lithuania.

\section{Figure 2. Country-level differences in interviewer perceptions of respondents}

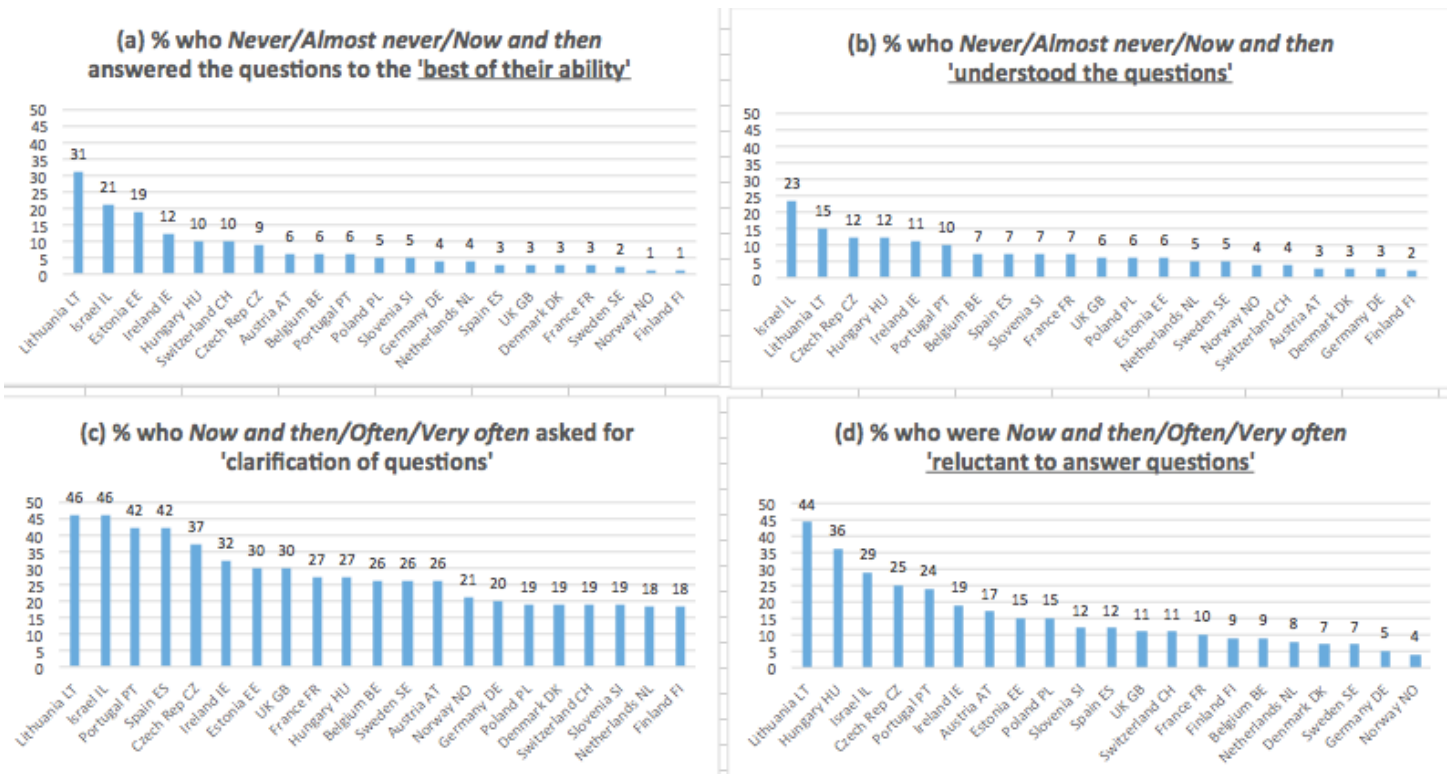

Finally, whether respondents had someone else present during the interview who 'interfered' in some way was examined. Overall 11 per cent of respondents were reported as having someone else present who 'interfered'. There was no difference in terms of the gender of the respondents. Of those aged under 20 years old, 17 per cent had someone else present who 'interfered' during the interview compared to 9 per cent of those aged 40-49 years old, 15 per cent of those aged $70-79$ and 20 per cent of those aged 80 years and older. Of those with no or the lowest level of qualifications, 21 per cent of people had someone else present compared to 6 per cent of people with the highest level of qualifications. Limited space prevents the showing of a chart but there were substantial differences between countries. Only 3 per cent of respondents in Sweden and 5 per cent in Denmark and Finland had someone else present who 'interfered' with the interview compared to 20 per cent of respondents in Estonia and Portugal and 27 per cent of respondents in Israel.

The presence of another person during an interview is likely, in part, to be related to the circumstances of the respondent and any support needs they may have. Of course, whilst the 'interference' during the interview may be supportive, it may also lead to the respondent giving particular answers. 


\section{Modelling the Likelihood of a 'Don't Know' Response to, Value and Attitude-Based Questions}

Focusing specifically on three example question types: factual (party respondent voted for at the last election); value (where respondent places themself on a 0-10 left/right scale); and attitude-based (trust in the European Parliament), multilevel logistic regression models were used to estimate the likelihood of a 'Don't know' response. The three questions where at least one response was 'Don't know' were also considered in a combined model.

The independent variables include respondent demographics, the interviewer observation paradata, and the two available interviewer characteristics (age and gender). The model allows us to separate the unexplained variation in 'Don't know' responses at the interviewer and country levels. The full random intercept model can be expressed generally as:

$$
\operatorname{Pr}\left(y_{i j k}=1 \mid x_{i j k}, v_{j k}, z_{k}, \mu_{k}, \mu_{j k}\right)=H\left(\beta_{0}+\beta_{1} x_{i j k}+\beta_{2} v_{j k}+\beta_{3} z_{k}+\mu_{k}+\mu_{j k}\right)
$$

where $y_{i j k}$ is the binary indicator of a 'Don't know' response for respondent $i$ interviewed by interviewer $j$ in country $k, x_{i j k}$ is the vector of covariates measured at the respondent level, $v_{j k}$ denotes covariates measured at the interviewer level, and $z_{k}$ denotes covariates measured at the country level, which are not included in the model. $\mu_{k}$ and $\mu_{j k}$ denote the random effects associated with the country and interviewer, respectively. Each random effect is assumed to follow a normal distribution with $\mu_{j k} \sim N\left(0, \sigma_{j k}^{2}\right)$ and $\mu_{k} \sim N\left(0, \sigma_{k}^{2}\right)$. $H(\cdot)$ is the logistic cumulative distribution function, which maps the linear predictor to the probability of a 'Don't know' $\left(y_{i j k}=1\right)$ response with $H(\eta)=$ $\exp (\eta) /\{1+\exp (\eta)\}$.

Using the null model (excluding all covariates), the intraclass correlation, or the proportions of unexplained variance in 'Don't know' responses that are due to interviewer and country-specific effects are estimated. The intraclass correlation (ICC) for countries is calculated as

$$
I C C_{k}=\frac{\sigma_{k}^{2}}{\sigma_{k}^{2}+\sigma_{j k}^{2}+\pi^{2} / 3}
$$

where $\pi^{2} / 3$ represents the constant level-one (i.e. respondent level) residual variance for the logistic distribution (Snijders and Bosker, 2012). The corresponding ICC for interviewers is calculated as

$$
I C C_{j k}=\frac{\sigma_{j k}^{2}}{\sigma_{k}^{2}+\sigma_{j k}^{2}+\pi^{2} / 3}
$$

It is important to acknowledge that the countries in the ESS employ a variety of sampling designs due to cost and sampling frame constraints. Some of these designs use cluster sampling to minimise interviewer travel between and within primary sampling units (PSUs) (ESS, 2016). It was not possible to access information about the allocation of interviewers to PSUs, but it is plausible that some interviewers were assigned to a single PSU, as is common in large-scale 
surveys. Thus, the interviewer intraclass correlations reported may reflect some area-level variation.

The random intercept models were fitted using the melogit command in Stata. The models were weighted to account for differences in inclusion probabilities and country population sizes. All models were estimated using mode-curvature adaptive Gauss-Hermite quadrature integration method with seven integration points (Skrondal and Rabe-Hesketh, 2004). Additional integration points produced similar results.

\section{Model Results}

The estimated variance components and intraclass correlations derived from the null model (excluding all respondent - and interviewer-level variables) for each target item are shown in Table 6 below.

Table 6. Estimated variance components and intraclass correlations (ICC) for 'Don't know' responses to the example factual, value and attitudebased questions.

\begin{tabular}{|c|c|c|c|c|}
\hline Full model & $\begin{array}{l}\text { Factual- } \\
\text { Based } \\
\text { Question. } \\
\text { Party } \\
\text { respondent } \\
\text { voted for at } \\
\text { the last } \\
\text { election }\end{array}$ & $\begin{array}{l}\text { Value-Based } \\
\text { Question. } \\
\text { Where would } \\
\text { you place } \\
\text { yourself on a 0- } \\
10 \text { left/right } \\
\text { scale }\end{array}$ & $\begin{array}{l}\text { Attitude- } \\
\text { Based } \\
\text { Question. } \\
\text { Trust in the } \\
\text { European } \\
\text { Parliament }\end{array}$ & $\begin{array}{l}\text { Combined } \\
\text { questions } \\
\text { model - at } \\
\text { least one } \\
\text { 'Don't know' } \\
\text { response }\end{array}$ \\
\hline $\begin{array}{l}\text { Variance } \\
\text { components } \\
\text { Country } \\
\text { Interviewer }\end{array}$ & $\begin{array}{l}0.68 \\
1.60\end{array}$ & $\begin{array}{l}0.42 \\
1.81\end{array}$ & $\begin{array}{l}0.64 \\
1.65\end{array}$ & $\begin{array}{l}0.30 \\
1.13\end{array}$ \\
\hline $\begin{array}{l}\text { Intraclass } \\
\text { correlations } \\
\text { Country } \\
\text { Interviewer }\end{array}$ & $\begin{array}{l}0.12 \\
0.29\end{array}$ & $\begin{array}{l}0.08 \\
0.33\end{array}$ & $\begin{array}{l}0.12 \\
0.30\end{array}$ & $\begin{array}{l}0.06 \\
0.24\end{array}$ \\
\hline
\end{tabular}

The variance components suggest that the majority of the unexplained variation is at the interviewer level. This is consistent across each of the three question types. Interviewers contribute 29 per cent and countries about 12 per cent of the variation in 'Don't know' responses to the factual item. The corresponding ICC estimates for the value question are 33 per cent and 8 per cent, and 30 per cent and 12 per cent for the attitude item, respectively. For the combined model (at least one 'Don't know' response to the three questions), the interviewer and country ICC values are 24 per cent and 6 per cent, respectively. ${ }^{5}$

Table 7 shows the results of the multilevel logistic regression analysis estimating the likelihood that respondents stated they 'Don't know'. As the odds ratios approach zero the likelihood of giving a 'Don't know' response becomes less and less compared to the reference group. 
Table 7. Likelihood of a 'Don't know' response to the selected factual, value and attitude-based questions.

\begin{tabular}{|c|c|c|c|c|}
\hline Odds Ratios & $\begin{array}{l}\text { 1. Factual-based } \\
\text { Question. Party } \\
\text { respondent voted } \\
\text { for at the last } \\
\text { election - named } \\
\text { a party (0) } \\
\text { compared to } \\
\text { 'Don't Know' (1). }\end{array}$ & $\begin{array}{l}\text { 2. Value-Based } \\
\text { Question. Where } \\
\text { would you place } \\
\text { yourself on a 0- } \\
10 \text { left/right scale } \\
\text { - Gave a number } \\
\text { (0) compared to } \\
\text { 'Don't Know' (1). }\end{array}$ & $\begin{array}{l}\text { 3. Attitude-Based } \\
\text { Question. Trust in } \\
\text { the European } \\
\text { Parliament - Gave } \\
\text { a number (0) } \\
\text { compared to } \\
\text { 'Don't Know (1). }\end{array}$ & $\begin{array}{l}\text { 4. Combined } \\
\text { questions model - } \\
\text { all three target } \\
\text { items (party, } \\
\text { left/right and } \\
\text { trust) and at least } \\
\text { one 'Don't Know' } \\
\text { response (1). }\end{array}$ \\
\hline \multicolumn{5}{|l|}{ Age (Ref: <20) } \\
\hline $20-29$ & 0.75 & $0.55^{*}$ & 0.88 & 0.82 \\
\hline $30-39$ & $0.56^{*}$ & $0.46^{*}$ & $0.60^{*}$ & $0.67^{*}$ \\
\hline $40-49$ & $0.50^{*}$ & $0.33^{*}$ & $0.58^{*}$ & $0.55^{*}$ \\
\hline $50-59$ & $0.34^{*}$ & $0.21^{*}$ & $0.45^{*}$ & $0.41^{*}$ \\
\hline $60-69$ & $0.20^{*}$ & $0.24^{*}$ & $0.56^{*}$ & $0.42^{*}$ \\
\hline $70-79$ & $0.20^{*}$ & $0.16^{*}$ & 0.83 & $0.40^{*}$ \\
\hline $80+$ & $0.16^{*}$ & $0.24^{*}$ & $1.66^{*}$ & $0.72^{*}$ \\
\hline \multicolumn{5}{|l|}{ Gender (Ref: Male) } \\
\hline Female & $1.88^{*}$ & $1.70^{*}$ & $1.71^{*}$ & $1.69^{*}$ \\
\hline \multicolumn{5}{|c|}{ Highest qualification (Ref: None/lowest) } \\
\hline ES-ISCED II & \begin{tabular}{|l|}
0.79 \\
\end{tabular} & $0.65^{*}$ & 0.72 & $0.70^{*}$ \\
\hline ES-ISCED-III & $0.65^{*}$ & $0.44^{*}$ & $0.52^{*}$ & $0.53^{*}$ \\
\hline ES-ISCED IV & $0.62^{*}$ & $0.30^{*}$ & $0.38^{*}$ & $0.43^{*}$ \\
\hline ES-ISCED V & $0.32^{*}$ & $0.20^{*}$ & $0.28^{*}$ & $0.29^{*}$ \\
\hline \multicolumn{5}{|c|}{ Clarification (Ref: No - Never/almost never) } \\
\hline $\begin{array}{l}\text { Yes - (Now and } \\
\text { then/often very often) }\end{array}$ & $1.42^{*}$ & $2.15^{*}$ & $2.17^{*}$ & $1.95^{*}$ \\
\hline \multicolumn{5}{|c|}{ Reluctant (Ref: No - Never/almost never) } \\
\hline $\begin{array}{l}\text { Yes - (Now and } \\
\text { then/often/very often) }\end{array}$ & 1.31 & $1.51^{*}$ & $1.45^{*}$ & $1.43^{*}$ \\
\hline \multicolumn{5}{|c|}{ Best ability (Ref: Yes - Often/very often) } \\
\hline $\begin{array}{l}\text { No (Now and } \\
\text { then/never/almost } \\
\text { never) }\end{array}$ & 1.11 & 0.87 & $0.70^{*}$ & 0.77 \\
\hline \multicolumn{5}{|c|}{ Understood (Ref: Yes - Often/very often) } \\
\hline $\begin{array}{l}\text { No (Now and } \\
\text { then/never/almost } \\
\text { never) }\end{array}$ & 1.50 & $2.05^{*}$ & $2.02^{*}$ & $1.92^{*}$ \\
\hline \multicolumn{5}{|c|}{ Person present who interfered (Ref: No) } \\
\hline Yes & 1.08 & $1.20^{*}$ & $1.26^{*}$ & 1.13 \\
\hline \multicolumn{5}{|c|}{ Interviewer gender (Ref: Male) } \\
\hline Female & 1.12 & $1.32^{*}$ & 1.17 & $1.20^{*}$ \\
\hline \multicolumn{5}{|c|}{ Interviewer age (Ref: <45) } \\
\hline $45-54$ & 0.83 & 0.81 & 1.05 & 0.93 \\
\hline $55-63$ & 0.79 & 0.84 & 1.00 & 0.89 \\
\hline $64+$ & 0.83 & $0.70^{*}$ & 1.20 & 0.95 \\
\hline Cons & $0.06^{*}$ & $0.14^{*}$ & $0.04^{*}$ & $0.24^{*}$ \\
\hline$N$ & 25,517 & 38,895 & 39,298 & 39,327 \\
\hline
\end{tabular}

${ }^{*}$ Significant to at least 0.05

Overall in relation to the example factual, value and attitude-based questions younger people are more likely to give a 'Don't know' response compared to older people. Although an exception are those people aged 80 years and older who were more likely to give a 'Don't know' response to the attitude question. Across all the questions women were more likely than men to give a 'Don't know' response. Those respondents with no or the lowest level of qualifications were consistently more likely to give a 'Don't know' response to all the questions. 
Those respondents who asked for clarification were more likely to state that they 'Don't know' to at least one of the three questions. Respondents who were perceived as being reluctant to answer questions and/or were perceived as not understanding all the questions were more likely to answer 'Don't know' to the value-based and attitude-based questions. Those respondents who were perceived to be not answering the questions to the best of their ability were less likely to give a 'Don't know' response to the attitude-based question. This may be linked to the respondent not particularly caring about their answers but wanting to give what they perceived to be a meaningful answer. Of course, caution is needed concerning the direction of the causation here; given the nature of the survey interview, it could be that those respondents who gave 'Don't know' responses were more likely to be seen as reluctant and/or not understanding the questions by the interviewers. The limitations of the available paradata prevent further analysis of this.

Respondents whose interviews were reported as being 'interfered' with by another person were more likely to answer 'Don't know' to the value and attitude-based questions than those respondents whose interviews were not 'interfered' with. It may be that the interference was prompted by the respondent giving a 'Don't know' answer. It is not possible from the ESS data to reveal what proportion of interviewees had another person present during the interview but who did not directly 'interfere'. However, research by Welkenhuysen-Gybels and Billiet (2001) has shown that the presence of a third person during an interview can be associated with measurement error.

Whilst there was considerable variation in the level of 'Don't know' responses at the interviewer level there was only limited evidence that the available interviewer characteristics (gender and age) were associated with 'Don't know' responses. Female interviewers were more likely to be given 'Don't know' answers from respondents to the value-based question compared to male interviewers. The older interviewers (aged 64+ years) were less likely to be given 'Don't know' answers compared to the youngest interviewers (aged <45 years), but this was only apparent for the value-based question. As discussed below, further analysis of interviewer characteristics would be of value but the available paradata is limited.

\section{Discussion and Implications}

The findings from the analysis of the differences in 'Don't know' responses between countries and interviewers and evidence from the interviewer observation paradata are particularly revealing and highlight the challenge for survey designers and analysts including for those conducting international comparative research.

Supporting findings from previous research, in general younger people, women and people with no or low levels of education qualifications were more likely to give a 'Don't know' response. In addition, substantial levels of 'Don't know' answers were given across all types of questions - factual, value and attitudebased. In relation to factual-based questions, it is likely that respondents who answer 'Don't know' do not have the information required to provide an answer, or it may relate to them not wanting to reveal certain information. $A$ 
'Don't know' response to value- and attitude-based questions are likely to relate to the respondent being uncertain, ambivalent, indifferent or not wanting to answer. As such the issue is more complex than simply missing data.

The interviewer observation paradata suggests that most of the respondents understood the questions and answered them to the best of their ability. Overall older people and those with no or low-level education qualifications were more likely to be viewed by their interviewer as having difficulties understanding questions, to ask for clarification and to be reluctant to answer. There were a small proportion of respondents who did not seem to engage with the survey interview in terms of answering questions to the best of their ability. This clearly raises questions about the accuracy of the data.

The interviewer and the country level context are important in relation to the variations in the level of 'Don't know' responses. The substantial amount of interviewer variation is largely unexplained as the basic characteristics of the interviewers (age and gender) were only modestly related to 'Don't know' responses and did not substantially reduce the variation. It would be of value to have more information on interviewer characteristics to explore the differences further.

The country-level variations highlight the contextual differences, which may include levels of access to information about political issues and also the freedom to express political views in different countries. There is some evidence of clustering with higher levels of 'Don't know' responses from people in Eastern European countries. In relation to the high level of respondents in Israel answering 'Don't know' to the question about personal trust in the European Union, this in part may be explained by Israel's political and geographic distance from Europe. It is also notable that Israel had relatively high levels of respondents who were: not perceived as understanding the questions, asked for clarification and who had another person present during the interview.

The country-level differences in the levels of respondents answering questions to the best of their ability, the extent to which respondents appear to understand the questions, and the frequency with which they ask for clarification and are reluctant to answer are also striking. Clearly further research that could examine the impact of the other contextual factors would be of value. Across the different countries the extent to which interviews are 'interfered' with by someone else being present also varies considerably. This may also be impacting on the accuracy of the data collected.

Whilst answering 'Don't know' and asking for clarification is likely to reflect respondents' difficulties in understanding a question, it also might reflect the critical engagement of respondents with the issues raised by the question. The respondent is perhaps taking a more evaluative position rather then simply not being engaged or not caring. This is linked to the greater likelihood of a 'Don't know' response when there was someone else present who 'interfered' with the interview. As outlined above, research by Sturgis et al., (2014) has identified 'hidden don't know' responses to survey questions which were more prevalent amongst those respondents who claimed to have an interest in the issues the questions referred to. 


\section{Ways Forward for Survey Methods}

The implications of the findings are far reaching for the analysis of survey data and the robustness of estimates of public knowledge, values and attitudes. Firstly, users of survey data should take account of 'Don't know' responses and the variations at the interviewer and country levels in their analysis especially when using cross-national data. This could involve including paradata and interviewer characteristics in statistical models as control variables.

Secondly, the interviewer and country level variations in the level of 'Don't know' responses have important implications in terms of the methodology of surveys and highlight the need for effective questionnaire design and robust training and testing to ensure consistency across interviewers and countries.

Thirdly, different respondents, including older people, may need additional help when responding to certain types of survey questions. Methodological innovations could include additional support and bespoke interviewer prompts for those types of respondent who are known to be likely to find answering certain survey questions a challenge - although, of course, without affecting the objectivity of the interview process. This could include ensuring respondents have the prior knowledge required to understand a question. It is essential to ensure that the survey questions are clear and straightforward to understand. Reducing the cognitive effort required to answer a question can lead to reducing the level of 'Don't know' responses. However, this does not mean just making the questions shorter. As research by Harmon (2001) has shown, longer and more complex questions, which include a fuller explanation or a vignette of the issue and additional response options, are associated with fewer 'Don't know' responses. See also Lenzner (2012). Conversational interviewing based approaches would also help, where interviewers are able to provide additional information to interviewees (Mittereder et al., 2017; West et al., 2018).

Fourthly, given the importance of interviewer observation paradata to the understanding of respondents' answers to survey questions, more surveys should include the collection of paradata at the individual question level. When respondents do give a 'Don't know' response follow up exploratory questions could be asked about the reason for such a response. This should also include follow-up data to explore how those respondents who initially answered 'Don't know' reached a directional answer.

The importance of survey design also includes on-line surveys where the design and layout have been shown to be associated with the level of 'Don't know' responses (Heerwegh, 2005). Given the growth in on-line surveys this is of particular importance. On-line surveys could include additional information and follow up questions for respondents' giving 'Don't know' answers including through the use of virtual interviewers and other communication tools.

In conclusion it is clear that analysts of public attitudes and users of survey data need to know more about 'Don't know' answers to questions. Simply discouraging 'Don't know' answers or coding them all as non-directional responses or missing data is likely to lead to measurement error in the 
estimates of public knowledge, attitudes and values.

\section{Limitations}

There are a number of limitations to the research. Firstly, the facts, values and attitudes asked about in the ESS are not exhaustive and so it would be useful to apply the analytical approach used to other surveys that cover a wider range of facts, values and attitudes.

Secondly, the analysis is reliant on the quality of the observation data from the interviewers. In the 2014 ESS there were 2,108 interviewers each completing an average of 19 interviews (ranging from an average of 8 interviews in the Czech Republic to an average of 24 in Switzerland). Whilst research by Sinibaldi et al., (2013) found only limited inconsistencies in observational data generated by differences between survey interviewers, other research has shown how the quality and consistency of responses during an interview can vary between observers (Clark et al., 2009; Loosveldt, 1999; West and Li 2019). A related issue is that the paradata about how the respondent answered and engaged with questions is produced by the interviewer only once the interview has been completed. It would be of value if the observation data were specific to each question. Further information on interviewer characteristics would also be of value. See Beullens and Loosveldt (2016) for further discussion of the interview process in the ESS.

Thirdly, if a respondent answers with a 'Don't know' response, it may influence the interviewers' observations of, for example, the respondent not understanding questions. Research by Beullens et al., (2008) and Beullens and Loosveldt $(2013 ; 2016)$ using the ESS found substantial levels of variation at the interviewer level including in relation to the speed of a survey interview. The ICC between the interviewers and their observations across different interviews was examined (see Appendix Table A3). The interviewers themselves have high ICCs, which suggests that some interviewers were more likely to observe (and record) respondents not answering to the best of their ability, being reluctant to answer, asking for clarification and not understanding the questions. This could be due to the varying compositions of respondents that interviewers were assigned to (respondents were not randomly assigned to interviewers in the ESS), and perhaps some interviewers were just more likely to perceive or not perceive, record or not record, certain types of response behaviour than other interviewers.

Finally, there is also the issue of language translation and the equivalence of the meaning of questions and response options including 'Don't know'. As outlined, the ESS question translations are piloted and tested. However, research has questioned the way concepts and scales can be interpreted differently in different languages and, for example, by men and women (Idler and Benyamini, 1997; Jilke et al., 2015).

\section{Acknowledgements}

We would like to thank the European Social Survey and its respondents (ESS Round 7: Norwegian Centre for Research Data). 


\section{References}

AAPOR (2017). An Evaluation of 2016 Election Polls in the U.S. American Association for Public Opinion Research. https://www.aapor.org/EducationResources/Reports/An-Evaluation-of-2016-Election-Polls-in-the-U-S.aspx

Alvarez, M.R. and Brehm, J. (2002). Hard Choices, Easy Answers: Values, Information, and American Public Opinion. Princeton University Press, Princeton.

Alwin, D.F. (2007). Margins of Error. A Study of Reliability in Survey Measurements. John Wiley, Hoboken, New Jersey.

Arcuri, L., Castelli, L., Galdi, S., Zogmaister, C. and Amadori, A. (2008). Predicting the vote: implicit attitudes as predictors of the future behavior of decided and undecided voters. Political Psychology 29, 3, pp. 369-387.

Bassili, J.N. and Fletcher, J.F. (1991). Response-time measurement in survey research a method for CATI and a new look at non attitudes. Public Opinion Quarterly, 55, pp. 331-346.

Beullens, K. and Loosveldt, G. (2016). Interview Effects in the European Social Survey. Survey Research Methods 10, 2, pp. 103-118.

Beullens, K. and Loosveldt, G. (2013). Assessing interviewer variance and its implication for data collection. 12.10. Katholieke Universiteit Leuven, Belgium, ESS-DACE.

Beullens, K., Loosveldt G., Vandenplas C. and Stoop I. (2018). Response Rates in the European Social Survey: Increasing, Decreasing, or a Matter of Fieldwork Efforts? Survey Methods: Insights from the Field. Online first https://surveyinsights.org/?p=9673

Beullens, K., Symons, K. and Loosveldt, G. (2008). Can we rely on the interviewers' opinions about the respondent to assess survey quality? Centre of Sociological Research, Katholieke Universiteit, Leuven, Belgium.

Bishop, G.F. (2004). The Illusion of Public Opinion: Fact and Artifact in American Public Opinion Polls. Rowman and Littlefield, Lanham, MD.

Bradburn, N.M. and Sudman, S. (1988). Polls and Surveys: Understanding What They Tell Us. Jossey-Bass, San Francisco.

Bryan, M.L. and Jenkins, S.P. (2016). Multilevel Modelling of Country Effects: A Cautionary Tale. European Sociological Review, 32, 1, pp. 3-22.

Cancela, J. and Geys, B. (2016). Explaining voter turnout: A meta-analysis of national and subnational elections. Electoral Studies, 42, 264-275.

Clark, A., Holland, C., Katz. J. and Peace, S. (2009). Learning to see: Lessons from a participatory observation research project in public spaces. International Journal of Social Research Methodology 12, pp. 345-360. 
Converse, P.E. (1970). Attitudes and Non-Attitudes: Continuation of a Dialogue. In: Tufte, E.R. (Eds.), The Quantitative Analysis of Social Problems. Addison-Wesley, Reading, MA. pp.168-189

Converse, J.M. and Presser, S. (1986). Survey Questions: Handcrafting the Standardized Questionnaire. Sage, California.

Couper, M. P. (2008). Designing Effective Web Surveys, Cambridge: Cambridge University Press

Couper, M. (1998). Measuring survey quality in a CASIC environment. Proceedings of the Survey Research Methods Section of the American Statistical Association, pp. 41-49.

Couper, M. and De Leeuw E. (2003). Nonresponse in cross-cultural and crossnational surveys. In Harkness J. van de Vijve, F. J. R. and Mohler, P. Ph. (eds.) Cross-Cultural Survey Methods. New Jersey: John Wiley. pp. 157-177.

Couper, M. and Kreuter, F. (2013). Using paradata to explore item level response times in surveys. Journal of the Royal Statistical Society Series A, 176, pp. 71-286.

Craig, S.C., Kane, J.G. and Martinez, M.D. (2002). Sometimes you feel like a nut, sometimes you don't: Citizens' ambivalence about abortion. Political Psychology 23, pp. 285-301.

Curtice, J. and Sparrow, N. (2010). The past matters: eliminating the proLabour bias in British opinion polls. International Journal of Market Research 52, 2, pp. 169-189.

ESS (2016). Sampling European Social Survey. (Available from http://www.europeansocialsurvey.org/methodology/ess methodology/sampling .html)

Festinger, L. (1957). A Theory of Cognitive Dissonance. Row and Peterson, Evanston.

Franklin, M. (2004). Voter turnout and the dynamics of electoral competition in established democracies since 1945. Cambridge: Cambridge University Press.

Gilljam, M. and Granberg, D. (1993). Should We Take Don't Know For An Answer? Public Opinion Quarterly 37, pp. 348-357.

Groves, R.M. and Heeringa, S.G. (2006). Responsive design for household surveys: tools for actively controlling survey errors and costs. Journal of the Royal Statistical Society Series A 169, pp. 439-457.

Haan, M., Ongena, Y.P., Vannieuwenhuyze, J.T.A, and Glopper, K de (2017). Response Behavior in a Video-Web Survey: A Mode Comparison Study. Journal of Survey Statistics and Methodology, 5, 1, pp. 48-69. 
Harmon, M. D. (2000). Poll Question Readability and ‘Don't Know' Replies. International Journal of Public Opinion Research 13, 1, pp. 72-79.

He, J., F. J. van de Vijver, A. D., Espinosa, A., Abubakar, R., Dimitrova, B. G., Adams, A., Aydinli, K., Atitsogbe, I., Alonso-Arbiol, M., Bobowik, R., Fischer, V., Jordanov, S., Mastrotheodoros, F., Neto, Y. J., Ponizovsky, J., Reb, S. Sim, L., Sovet, D., Stefenel, A. O., Suryani, E. Tair and A. Villieux. (2014). Socially Desirable Responding: Enhancement and Denial in 20 Countries. CrossCultural Research 49, 3, pp. 227-249.

Heerwegh, D. (2005). Web Surveys. Explaining and Reducing Unit Nonresponse, Item Nonresponse and Partial Nonresponse, Katholieke Universiteit Leuven, Belgium.

Holbrook, A.L. and Krosnick, J.A. (2010). Social desirability bias in voter turnout reports. Public Opinion Quarterly 74, 1, pp. 37-67.

Holbrook, A.L. and Krosnick, J.A. (2005). Meta-psychological vs. operative measures of ambivalence: Differentiating the consequences of perceived intrapsychic conflict and real intra-psychic conflict. In: Craig, S.C., Martinez, M.D., (Eds.), Ambivalence and the Structure of Public Opinion. Palgrave Macmillan, New York. pp. 73-103.

Idler, E.L. and Benyamini, Y. (1997). Self-rated health and mortality: A review of twenty-seven community studies. Journal of Health and Social Behavior 38, pp. 21-37.

Inglehart, R.F. (2003). Culture and Social Change: Findings from the Value Surveys. Brill Academic Publishers, Leiden.

Inglehart, R. (2010). Changing Human Beliefs and Values, 1981-2007. Mexico: DF.

International IDEA (2017). Voter Turnout Trends Around the World. Stockholm: International IDEA.

Ipsos Mori (2016). Perceptions are not reality: Things the world gets wrong. Ipsos Mori, London.

Jilke, S., Meuleman, B. and Van de Walle, S. (2015). We Need to Compare, but How? Measurement Equivalence in Comparative Public Administration. Public Administration Review, 75, pp. 36-48.

Johnson, A.J. (2014). Ambivalence, political engagement and context. Political Studies 62, pp. 502-521.

Johnson, T., and van de Vijver, F. J. (2003). Social desirability in crosscultural research. In J. Harness, F. J. van de Vijver, and Mohler, P. (Eds.), CrossCultural Survey Methods. New York: Wiley. pp. 193-202 
Knowles, E.S. and Condon, C.A. (1999). Why people say 'yes': a dual-process theory of acquiescence. Journal of Personality and Social Psychology 77, pp. 379-386.

Kreuter, F. (2018a). Paradata. In Vanette, D.L. and Krosnick, J.A. (Eds) The Palgrave Handbook of Survey Research. Cham, Switzerland: Palgrave Macmillan, pp. 529-536.

Kreuter, F. (2018b). Getting the Most Out of Paradata. In Vanette, D.L. and Krosnick, J.A. (Eds) The Palgrave Handbook of Survey Research. Cham, Switzerland: Palgrave Macmillan, pp. 193-198.

Krosnick, J.A. (1991). Response strategies for coping with the cognitive demands of attitude measures in surveys. Applied Cognitive Psychology 5, pp. 213-236.

Krosnick, J.A., Holbrook, L., Allyson, M.K., Berent, R.T., Carson, W.M.H., Kopp, R.J., Cameron, M.R., Presser, S., Ruud, P.A., Kerry, S.V., Moody, W.R., Green, M.C. and Conaway, M. (2002). The impact of no opinion response options on data quality: non-attitude reduction or an invitation to satisfice? Public Opinion Quarterly 66, pp. 371-403.

Kuha, J., Butt, S., Katsikatsou, M., and Skinner, C. J. (2018). The effect of probing "Don't Know" responses on measurement quality and nonresponse in surveys. Journal of the American Statistical Association, 113, pp. 26-40.

Lavine, H., (2001). The electoral consequences of ambivalence toward presidential candidates. American Journal of Political Science 45, pp. 915-929.

Lenzner, T. (2012). Effects of Survey Question Comprehensibility on Response Quality. Field Methods, 24, pp. 409-428.

Loosveldt, G. (1999). The Interviewer as an Informant About Interview Process. Association for Survey Computing, International Conference Proceedings edited by Christie, C. and Francis, J.

Luijkx, R., Halman, L., Sieben, I., Brislinger, E. and Quandt, M. (2016). European Values in Numbers Trends and Traditions at the Turn of the Century European Values Studies, Volume: 16. Leiden: Brill.

Luskin, R.C. and Bullock, J.G. (2011). “Don't Know” Means “Don't Know”: DK Responses and the Public's Level of Political Knowledge. The Journal of Politics 73:2, pp. 547-557.

Lyness, K. S., and Brumit Kropf, M. (2007). Cultural Values and Potential Nonresponse Bias: A Multilevel Examination of Cross-National Differences in Mail Survey Response Rates. Organizational Research Methods, 10, 2, pp. 210-224.

Malhotra, N., Krosnick, J.A. and Thomas, R.K. (2009). Optimal design of branching questions to measure bipolar constructs. Public Opinion Quarterly, 73, pp. 304-324. 
Martinez, M., Gainous, J. and Craig, S. (2012). Measuring ambivalence about Government. In: Aldrich, J., McGraw, K. (Eds.), Improving Public Opinion Surveys. Princeton University Press, Princeton, pp. 238-259.

Miller, M. K. and Orr, S. K. (2008). Experimenting with a "Third Way" in political knowledge estimation. Public Opinion Quarterly, 72, 4, pp. 768-780.

Mittereder, F., Durow, J., West, B.T., Kreuter, F. and Conrad, F.G. (2017). Interviewer-respondent interactions in conversational and standardized interviewing. Field Methods, 30, 1, pp. 3-21.

Nicolaas, G. (2011). Survey Paradata: A review. National Centre for Social Research, NCRM 017, Southampton.

Noelle-Neumann, E. (1984). The Spiral of Silence. Public Opinion-Our Social Skin. The University of Chicago Press, Chicago.

O'Muircheartaigh, C. and Campanelli, P. (1998). A multilevel exploration of the role of interviewers in survey non-response. Journal of the Royal Statistical Society Series A 162, pp. 437-446.

Robison, J. (2015). Who Knows? Question Format and Political Knowledge, International Journal of Public Opinion Research, 27, 1, pp. 1-21.

Robmann, J. Gummer, T. and Silber, H. (2017). Mitigating Satisficing In Cognitively Demanding Grid Questions: Evidence From Two Web-Based Experiments. Journal of Survey Statistics and Methodology, 6, 3, pp. 376-400

Rudolph, T.J. and Popp, E. (2007). An information processing theory of ambivalence. Political Psychology 28, pp. 563-585.

Schuman, H. and Presser, S. (1981). Questions and Answers in Attitude Surveys. Academic Press, New York.

Shoemaker, P., Eichholz, M. and Skewes, E.A. (2002). Item nonresponse: Distinguishing Between Don't Know and Refuse. International Journal of Public Opinion Research 14, 2, pp. 193-201.

Silver, N. (2016). Election Update: Where Are The Undecided Voters? Election Update: Where Are The Undecided Voters? (Available from http://fivethirtyeight.com/features/election-update-where-are-the-undecidedvoters/)

Sinibaldi, J., Durrant, G.B. and Kreuter, F. (2013). Evaluating the Measurement Error of Interviewer Observed Paradata. Public Opinion Quarterly 77, 1, pp. 173-193.

Snijders, T. and Bosker, R. (2012). Multilevel Analysis: An Introduction to Basic and Advanced Multilevel Modeling. Sage, London. 
Skrondal, A. and Rabe-Hesketh, S. (2004). Generalized Latent Variable Modeling: Multilevel, Longitudinal, and Structural Equation Models. Chapman and Hall, London.

Sturgis, P. and Smith, P. (2010). Fictitious Issues Revisited: Political Interest, Knowledge and the Generation of Nonattitudes. Political Studies 58, pp. 6684.

Sturgis, P., Baker, N., Callegaro, M., Fisher, S., Green, J., Jennings, W., Kuha, J., Lauderdale, B. and Smith, P. (2016) Report of the Inquiry into the 2015 British general election opinion polls. NCRM, British Polling Council, Market Research Society.

Sturgis, P., Roberts, C. and Smith, P. (2014). Middle Alternatives Revisited: How the neither/nor Response Acts as a Way of Saying 'I Don't Know'? Sociological Methods and Research, 43, 1, pp. 15-38.

Tourangeau, R., Rips, L.J. and Rasinski, K. (2000). The Psychology of Survey Response. Cambridge University Press, New York.

Turner, G., Sturgis, P. and Martin, D. (2015). Can Response Latencies Be Used to Detect Survey Satisficing on Cognitively Demanding Questions? Journal of Survey Statistics and Methodology, 3, 1, 1, pp. 89-108.

Welkenhuysen-Gybels, J. and Billiet, J. (2001). The impact of third party presence in survey interviews on the measurement of political knowledge. Acta Politica 36, pp. 287-306.

West, B.T. and Li, D. (2019). Sources of Variance in the Accuracy of Interviewer Observations. Sociological Methods \& Research, 48, 3, pp. 485533

West, B.T., Conrad, F.G., Kreuter, F. and Mittereder, F. (2018). Can conversational interviewing improve survey response quality without increasing interviewer effects? Journal of the Royal Statistical Society. Series A, Statistics in Society, 181, 1, pp. 181-203.

Zeglovits, E. and Schwarzer, S. (2016). Presentation matters: how mode effects in item non-response depend on the presentation of response options. International Journal of Social Research Methodology, 19, 2, pp. 191-203. 


\section{Appendix}

Table A1 shows summary statistics for respondents, interviewers, and countries.

Table A1. Summary statistics of respondents, interviewers, and countries for 'Don't Know' analysis.

\begin{tabular}{|l|l|}
\hline & Overall \\
\hline Number of respondents & 40,185 \\
\hline Number of interviewers & 2108 \\
\hline Number of countries & 21 \\
\hline $\begin{array}{l}\text { Respondents per interviewer } \\
\text { Minimum }\end{array}$ & 19.06 \\
Maximum & 1 \\
\hline $\begin{array}{l}\text { Interviewers per country } \\
\text { Mean } \\
\text { Minimum } \\
\text { Maximum }\end{array}$ & 144 \\
\hline
\end{tabular}


Table A2 shows the percentage of 'Don't Know' responses by interviewer and country. The attitude item exhibits the widest range of 'Don't Know' rates by country, with a minimum 'Don't Know' rate of 1 per cent (Belgium) and a maximum rate of 35 per cent (Israel).

Table A2. Percentage of 'Don't Know' responses to factual, value, and attitude-based questions by interviewer and country.

\begin{tabular}{|l|l|l|l|}
\hline & $\begin{array}{l}\text { Factual- } \\
\text { based } \\
\text { question }\end{array}$ & $\begin{array}{l}\text { Value-based } \\
\text { question }\end{array}$ & $\begin{array}{l}\text { Attitude- } \\
\text { based } \\
\text { question }\end{array}$ \\
\hline $\begin{array}{l}\text { \% 'Don't Knows' by } \\
\text { interviewer } \\
\text { Mean }\end{array}$ & 5.14 & 9.70 & 6.70 \\
SD & 11.86 & 14.76 & 11.12 \\
Minimum & 0.00 & 0.00 & 0.00 \\
Maximum & 100.00 & 100.00 & 100.00 \\
\hline \% 'Don't Knows' by country & 5.69 & 9.77 & 7.78 \\
Mean & 4.59 & 7.49 & 6.92 \\
SD & 0 & 2.30 & 0.80 \\
Minimum & 16.95 & 30.67 & 35.36 \\
Maximum & &
\end{tabular}


Table A3 shows the estimated variance components and intraclass correlations of interviewer responses about respondent behaviour.

Table A3. Estimated variance components and intraclass correlations (ICC) of interviewer responses about respondent behaviour.

\begin{tabular}{|l|l|l|l|l|l|}
\hline Full Model & $\begin{array}{l}\text { Respondent } \\
\text { tried to } \\
\text { answer } \\
\text { questions to } \\
\text { best of their } \\
\text { ability? }\end{array}$ & $\begin{array}{l}\text { Overall, did } \\
\text { you feel that } \\
\text { the } \\
\text { respondent } \\
\text { understood } \\
\text { the } \\
\text { questions? }\end{array}$ & $\begin{array}{l}\text { Did the } \\
\text { respondent } \\
\text { ask for } \\
\text { clarification } \\
\text { on any } \\
\text { questions? }\end{array}$ & $\begin{array}{l}\text { Did you feel } \\
\text { that the } \\
\text { respondent } \\
\text { was } \\
\text { reluctant to } \\
\text { answer any } \\
\text { questions? }\end{array}$ & $\begin{array}{l}\text { Respondent } \\
\text { had } \\
\text { someone } \\
\text { else present } \\
\text { during the } \\
\text { survey } \\
\text { interview } \\
\text { who } \\
\text { 'interfered' in } \\
\text { some way. }\end{array}$ \\
\hline $\begin{array}{l}\text { Variance } \\
\text { components }\end{array}$ & & & & & \\
$\begin{array}{l}\text { Country } \\
\text { Interviewer }\end{array}$ & 0.72 & 0.32 & 0.27 & 0.82 & 0.30 \\
\hline $\begin{array}{l}\text { Infraclass } \\
\text { correlations }\end{array}$ & 1.99 & 1.24 & 1.69 & 1.56 \\
\hline $\begin{array}{l}\text { Country } \\
\text { Interviewer }\end{array}$ & 0.68 & & & & \\
\hline
\end{tabular}




\footnotetext{
${ }^{1}$ Details of the survey, questionnaire and translation standards are available here: http://www.europeansocialsurvey.org/

${ }^{2}$ See http://www.europeansocialsurvey.org/methodology/ess_methodology/sampling.html

${ }^{3}$ The term 'Interfered' describes where there is someone else present during the interview who has some input in terms of offering opinions or comments or if the respondent looks to them for approval or disapproval. The ESS guidance suggests that ideally no one else is present during the interview.

${ }^{4}$ Evidence suggests people often overestimate the levels of migration in their local area (Ipsos Mori, 2016).

${ }^{5}$ The estimated variance components and ICCs for the saturated model (including all respondent- and interviewer-level covariates, yielded similar results. Moreover, the inclusion of the interviewer characteristics (age and gender) did not yield a noticeable reduction in the between-interviewer variance (results not shown).
} 